\title{
Economics of Religious Participation in the Rural South
}

\author{
Anil Rupasingha and David Freshwater*
}

\begin{abstract}
This paper analyzes individuals' religious behavior from an economic perspective to explain religious behavior among residents of the rural South of the United States. Religious participation decisions of individuals in the rural South are analyzed within an allocation of time framework. Empirical estimation uses an ordered probit model and survey data collected from a sample of residents of the rural South. Results show that economic variables as well as noneconomic variables account for variation in religiosity. An individual's age, educational attainment, sex, marital status, race, income, faith in God and afterlife, intensity of belief, and civic participation are strongly associated with religious participation.
\end{abstract}

\section{INTRODUCTION}

Traditionally, religious behavior has been considered to be beyond the boundaries of economic science, although even the father of modern neoclassical economics, Adam Smith, noted its relevance to economics (Anderson 1988). More recently, discussions of the interdependence of religion and economic behavior are emerging with some frequency in economic literature. There has been a rise in the number of economists seeking to apply the insights of economic theory to religious behavior. Most of these studies on religious behavior utilize a Becker-style allocation of time framework. This approach has been used to expand the domain of economics into a wide range of areas, including the economics of crime, marriage, morality, norms and conventions, and religion (Becker 1976; Akerlof 1980; Hirschleifer 1985). Azzi and Ehrenberg (1975) are among the first economists to empirically investigate religiosity in an economic allocation of time model framework. Related empirical studies were conducted by Ulbrich and Wallace (1983), Sullivan (1985), and Sawkins, Seaman, and Williams (1997). Smith, Sawkins, and Seaman (1998) conducted a study of cross-country variation in religious participation.

The objective of the present study is to utilize an allocation of time framework to analyze religious service attendance by residents of the rural South of the United States. The balance of the paper is organized as follows. Section II outlines the theoretical ideas found in the religion and economics literature. Section III presents an account of the religiosity in the rural South. Section IV presents a model

\footnotetext{
*Anil Rupasingha is a postdoctoral scholar for TVA Rural Studies in the Department of Agricultural Economics at the University of Kentucky. David Freshwater is the program manager for TVA Rural Studies and a professor in the Department of Agricultural Economics at the University of Kentucky. An earlier draft of this paper was presented at the 45th North American Meetings of the Regional Science Association International in Santa Fe, NM, in November of 1998. The views expressed herein are the authors and do not necessarily represent the views of their institutions. The authors would like to thank three anonymous reviewers for comments that improved an earlier draft and Celeste Sullivan for editorial assistance.
} 
of religious participation and a description of data and variables used in the empirical analysis. Section V discusses the results, with the conclusion in Section VI.

\section{OVERVIEW}

One body of early wisdom (from David Hume to Karl Marx and Sigmund Freud) describes religious behavior as primitive, nonscientific, and nonrational. Stark, Iannaccone, and Finke (1996, p. 433) point out three "stylized facts" that this conventional wisdom emphasized: (i) religion must inevitably decline as science and technology advance; (ii) individuals become less religious and more skeptical of faith-based claims as they acquire more education, particularly more familiarity with science; and (iii) membership in deviant religions is usually the consequence of indoctrination (leading to aberrant values) or abnormal psychology (due to trauma, neurosis, or unmet needs).

The claim of these early writers that religious behavior is irrational has been challenged by both theoretical and empirical evidence (Stark, Iannaccone, and Finke 1996). Researchers have found that there is no evidence to prove that those diagnosed as in need of immediate psychotherapy were more likely to attend church, or to score high on an index of religious orthodoxy (Stark 1971). In a survey of published empirical literature, Bergin (1983) finds that most studies reported a positive relationship between piety and mental health. Stark, Iannaccone, and Finke (1996) present solid evidence that the relationship between educational attainment and religiosity is positive, not negative, and that professionals (university faculty) in "hard" sciences are more religious than those who are in "soft" sciences and humanities.

The importance of religion in economics has entered a new era with the emergence of concepts such as social capital, reciprocity, cooperation, and selforganization, since religion plays an important role in shaping individual behavior. All religions work to instill certain values, morals, and behaviors in their followers. These values, beliefs, and morals are seen in most aspects of human behavior: diet, dress, and grooming; sexual conduct, procreation, and family life; rest, recreation, and social interactions; and education, commerce, and political action (Iannaccone 1996). Quoting from Adam Smith's Theory of Moral Sentiments, Anderson (1988) points out that religious belief provides strong incentives to follow moral strictures (honesty, benevolence, restraint from violence) that help support civil society. The most significant contribution of Adam Smith to the topic of religion and economics was to lay the foundation for the economic analysis of religion in The Wealth of Nations (Iannaccone 1998). Smith applied the market framework to religious denominations and individual churches.

Religious behavior helps overcome the obstacles to collective action problems, such as the prisoner's dilemma. It has been viewed as a vehicle for improving well-being and for discouraging free riding and shirking. Iannaccone (1996) argues that religious ethics and codes serve as a system of utility-maximizing rules that enhance group commitment and reduce free riding (by screening out less committed members and limiting access to competing activities). Forms of 
religious behavior, with direct economic implications, include: voluntary free labor for community activities, donations to public causes, subsidized educational facilities, and a tendency for specific types of economic enterprises to belong to specific religious groups (the Jewish diamond market in New York City is one example).

Some see religion as an obstacle to economic and community development in a democratic capitalistic society. Novak (1986) argues that Christianity, aligned with socialism, will not bring about economic development. Kuran (1997) notes that the economic and intellectual development in Islamic countries has lagged behind that of the West. Iannaccone (1996) says that some stricter religious rules restrict economic activity or impose nonproductive costs, and reduce efficiency. There are instances in which religions stifle cooperation among members of a community and, in turn, economic and community development. Deviant norms and contradictory beliefs among a heterogeneous population (i.e., members belong to several religions) can mitigate cooperation among individuals. For example, conflict between Israelis and Palestinians based on religion and ethnicity has hampered the economic progress in that region and impeded cooperation among the members of the two nationalities.

Religiosity of a population in a society may lead to reduced transaction costs. Conventional economic analysis assumes that transaction costs are zero, but in reality, transaction costs are rarely zero. The costs of negotiating, conducting, monitoring, and enforcing contracts, and the costs of finding out what the relevant prices are, are typically not zero (Harriss, Hunter, and Lewis 1995). When transaction costs are decreased, more exchange will take place, thus enlarging the scope of transactions and interactions. Low levels of interpersonal trust results in demand for more external controls, such as tougher law enforcement, security systems, and more pervasive and greater outlays on monitoring and enforcement. A shared religion may eliminate this problem. Religious institutions can monitor the behavior of their members, reward high levels of commitment, and penalize inappropriate behavior. Members are encouraged to monitor, advise, and encourage fellow members. And in contrast to other institutions, religions emphasize supernatural monitoring: "God is watching you" (Iannaccone 1996). Anderson (1998, p. 1069) states that belief in God constitutes a kind of internal moral enforcement mechanism. Adam Smith says religions tend to produce and distribute moral information about individual members and he describes an individual's moral reputation as a capital asset (as found in Anderson 1988). Therefore, according to Smith, a wealth-maximizing individual has an economic incentive to participate in religious activities.

Becker's (1965) pioneering work on household production provides a theoretical basis for economic analysis and much of the recent literature on religion and economics is grounded in this approach. Azzi and Ehrenberg's (1975) study utilized Becker's framework to examine church attendance in the United States. Variation in religious participation among economic agents is ascribed to three major motives: the "salvation motive," or afterlife consumption; the "consumptive 
motive;" and the "social pressure motive." Azzi and Ehrenberg (1975) test a model in which individuals draw their motivation for religious participation from the prospect of "afterlife consumption." They acknowledge that religious participation may yield immediate utility but emphasize that afterlife consumption may be the primary motive. Azzi and Ehrenberg's (1975) model has served as the cornerstone for most of the subsequent empirical studies on economics and religious behavior. Sullivan (1985), rejecting the "afterlife consumption" approach as unnecessary and not measurable, models religious behavior based on the assumption that it generates immediate utility. Ulbrich and Wallace (1983) provide additional testing of the afterlife hypothesis and conclude that the motives of participation are mixed and cannot be tied to any one motive. Sawkins, Seaman, and Williams (1997) adopt Sullivan's (1985) revision of Azzi and Ehrenberg's (1975) framework (religious activity generates immediate utility) and analyze church attendance decisions by individual economic agents within a Becker-style allocation of time framework. Iannaccone (1998) expands Azzi and Ehrenberg's (1975) model by incorporating "religious human capital" in arguing that an individual's participation in religious activities depends not only upon his or her inputs of time and goods, but also upon religious knowledge, familiarity with church ritual and doctrine, and friendship with fellow worshippers.

In this paper, we model religious behavior as a function of a "mixed bag" of motives. Although we have included economic and demographic variables that have traditionally been used to measure the consumptive motive, we avoid emphasizing a distinct consumptive motive and instead combine it with social capital or social pressure motives. We do not deny that there may be a valid conceptual distinction between the two, but we cannot identify empirical measures that clearly discriminate between the two concepts.

Further, it is reasonable to argue that we can embed any consumptive motive in a social capital motive, as all forms of economic benefits accrue to communities and individuals through their religious participation. A major advantage of the survey data set used in the analysis is that it asked questions about faith in God and how it affects day to day affairs, afterlife, and community and civic participation. We postulate that affirmative answers for these questions provide individuals with incentives to participate in religious services with salvation and social capital motives. Our model also slightly departs from existing literature by focusing on an expected utility framework. It assumes that the demand for religious service goods is dependent on individuals' expectations about the afterlife and their expectations about other individuals' behavior in a community.

\section{RELIGIOSITY IN THE RURAL SOUTH}

Researchers have argued that the southern United States remains a distinctive cultural region (Hurlbert 1989; Chalfant and Heller 1991). Southerners are said to be more regular in their church attendance than those living in other regions (Kanagy, Firebaugh, and Nelsen 1994). Fichter and Maddox (1965) argue that to be a Southerner is to participate in organized religion. They also describe 
religion in the South as pervasive and as "characterized by high visibility, conservatism and emotionalism" (Fichter and Maddox 1965, p. 359). According to Reed (1973, 1983, as found in Hurlbert 1989), southern distinctiveness is so strong that Southerners constitute an ethnic group in much the same way as Polish or Italian Americans do. The association of this culture with religion has been particularly strong in the rural South (Kanagy, Firebaugh, and Nelsen 1994).

These claims can be verified by comparing evidence from the Roper Starch survey of the rural South with 1996 Gallup Poll data for the whole nation. The percentage of respondents who attended religious services once a week, or more, is the same for the rural South as for the nation (39 percent). The percentage of persons who attended a few times a month, or monthly, was 29 percent in the rural South, compared with 17 percent in the nation. The percentage of persons who attended a few times a year, or less, was about 25 percent in the rural South, compared with 33 percent in the nation. The percentage of persons who did not attend at all was 8 percent in the rural South, compared with 10 percent in the nation.

The strength of belief in the rural South seems to be higher than the national average. The question "How important would you say religion is in your own life?" was asked in both surveys. Sixty-six percent of rural South residents said it is "very important," while 58 percent of the Gallup Poll respondents said it is "very important." The percentages of respondents who answered "fairly important" were the same for both surveys (27 percent), but the percentages of respondents who answered "not very important" were 14 percent for the national data, compared with 7 percent for the rural South data. The question "Have you been born again?" was posed in both surveys. Affirmative responses were substantially higher in the rural South (74 percent) than in the nation (41 percent).

\section{A MODEL OF RELIGIOUS PARTICIPATION}

The theoretical model presented below is a variation of the models presented in previous literature on the subject. Most of the previous models assume that the expected stream of benefits from religious participation is certain. ${ }^{1}$ This assumption is not appropriate since, in reality, an individual's decision regarding religious goods consumption is determined, in part, by expected future and/or afterlife benefits. Durkin and Greeley (1991) state that no individual decision involves more uncertainty than religious choice because information regarding the existence of God or the afterlife is imperfect. The respondent's information level is a function of his or her socioeconomic, demographic, attitudinal, and community factors. The individual's expectations of afterlife benefits, combined with present benefits of religious participation, dictate an optimal strategy upon which the individual will participate in religious activities.

These expectations can be incorporated into a utility maximization framework by using the expected utility theorem (Von Neumann and Morgenstern 1947). Under some additional hypotheses (Varian 1992), we can find a particular

\footnotetext{
${ }^{1}$ The only exception we are aware of is the study by Durkin and Greely (1991). They present a rational choice model of religious behavior that illustrates the special nature of the uncertainty inherent in religious choice.
} 
monotonic transformation of the standard utility function with the expected utility property. Incorporation of expectations requires the identification of the set of outcomes facing the consumer and the probability of each of these outcomes. We can calculate the expected utility of each outcome if we know the potential outcomes and the probabilities of each outcome. Each individual's risk preferences determine which outcome to choose. Suppose that an individual chooses two goods, consumption (C) and religious activities (S). The source of uncertainty in our utility function is $S_{t}$, the utility from the consumption of religious goods. The utility function can be written as

$$
E[u]=u\left(C_{t}\right)+v\left(S_{t}\right) \varepsilon,
$$

where $\varepsilon$ is a random variable. The second part of the right-hand side of the equation depicts the individual's subjective perception about the utility that he or she gets from consuming religious goods. These expected benefits from religious participation depend on the amount of information received by individuals from available sources. This particular specification follows the usual assumption of being additive across both time and states of nature (Varian 1992). Further, the utility of the composite consumption goods is considered to be nonstochastic. However, the utility from religious goods is unknown, and this uncertainty is captured in the stochastic part of the utility function, $\mathrm{v}\left(\mathrm{S}_{\mathrm{t}}\right) \varepsilon$. It is also assumed that $\mathrm{v}(0)=0$, suggesting that a consumer's utility is nonrandom in the absence of religious goods consumption.

Suppose also that the composite consumption good includes consumer goods and the individual's time for leisure. Without loss of generality, we assume that the total time available to the individual is divided between work and religious activities. The time constraint for the individual may be written as

$$
T=r_{t}+l_{t} \text {, and } r_{t}, l_{t} \geq 0 \text { for all } t \text { where } t=1,2, \ldots, n \text {. }
$$

$\mathrm{T}$ denotes the total time available per period, $\mathrm{r}_{\mathrm{t}}$ is the individual's allocation of time for religious activities, and $l_{t}$ is his or her hours of work. We also assume that if the individual does not spend time on religious activities, he will use that time at work and earn income. Therefore, following standard assumptions, the opportunity cost of religious activities is lost wages. The individual's income constraint may be written as

$$
\sum \frac{p C_{t}+w S_{t}}{(1+i)^{t-1}}=\sum \frac{w_{t}(T)}{(1+i)^{t-1}}
$$

where $\mathrm{p}$ denotes the price of the composite good, $\mathrm{w}$ is the individual's wage rate and the price paid for religious activities, and $i$ is the market rate of interest. The consumer maximizes his or her expected utility through the optimal choice of $C$ 
and S, subject to the income constraint. ${ }^{2}$ The first-order conditions give the necessary conditions for utility maximization. We also assume that the second-order sufficient conditions are satisfied.

It is evident from the first-order conditions (see Footnote 2 for derivation) that the two choice variables, C and S, are "separable" in the sense that one can be solved independently of the other. This "separability" between the $C$ and $S$ choices allows us to focus on our main objective of the study, the demand for religious activities. The individual chooses an optimal level of religious service goods $\left(\mathrm{S}^{*}\right)$ to maximize his or her total expected utility. Following previous research efforts (Azzi and Ehrenberg 1975; Sullivan 1985; Sawkins, Seaman, and Williams 1997), we use individuals' frequency of church or religious service attendance as a proxy variable to quantify the amount of religious service goods. The optimal level of religious service attendance is a function of an individual's soicoeconomic, demographic, attitudinal, and community factors, which determine each respondent's religious information level. These factors are captured in the vector of explanatory variables $X$, into a model of religious service attendance in the rural South, and expressed in the regression relationship

$$
y_{i}^{*}=\beta x_{i}+\mu_{i},
$$

where $y_{i}^{*}$ is the unobserved demand for religious service goods and $\mu$ is an error term.

The data used for the analysis were drawn from a survey of residents of the rural South of the United States. The survey was conducted in January and February of 1996 by Roper Starch Worldwide and was sponsored by TVA Rural Studies at the University of Kentucky. In total, 1,200 people were interviewed faceto-face in rural areas of Alabama, Georgia, Kentucky, Mississippi, North Carolina, South Carolina, Tennessee, and Virginia. The survey provides information on the respondents' socioeconomic characteristics and attitudes on various issues, including religion, employment, education, and job training. We used individuals' frequency of church or religious service attendance as a proxy variable to quantify the time devoted to religious activities by rural Southerners. We note, following other authors, that this proxy fails to capture other aspects of religious activity, such as time spent in private prayers and voluntary work. We are also aware, as with most survey questions concerning individuals' values and beliefs, that it is difficult to evaluate the overall accuracy of individuals' responses to religious questions. Individuals' demand for religious goods, or the intensity of participation in religious services, was formulated from the question in the survey "How

${ }^{2}$ The formation of the constrained optimization problem yields the equation

(A1) $\mathrm{L}=\mathrm{u}\left(\mathrm{C}_{\mathrm{t}}\right)+\mathrm{v}\left(\mathrm{S}_{\mathrm{t}}\right) \varepsilon+\lambda\left[\Sigma\left(\mathrm{w}_{\mathrm{t}}(\mathrm{T}) /(1+\mathrm{i})^{\mathrm{t}-1}\right)-\Sigma\left(\mathrm{pC}_{\mathrm{t}}+\mathrm{wS} \mathrm{s}\right) /(1+\mathrm{i})^{\mathrm{t}-1}\right]$ ，

with the following first-order conditions, assuming interior solutions,

(A1a) $\left(\partial \mathrm{L} / \partial \mathrm{C}_{\mathrm{t}}\right)=\mathrm{U}_{\mathrm{c}}-\lambda \Sigma \mathrm{p} /(1+\mathrm{i})^{\mathrm{t}-1}=0$

(A1b) $\left(\partial \mathrm{L} / \partial \mathrm{S}_{\mathrm{t}}\right)=\mathrm{U}_{\mathrm{s}} \mathrm{v}^{\prime}(.) \varepsilon-\lambda \Sigma \mathrm{w} /(1+\mathrm{i})^{\mathrm{t}-1}=0$

(A1c) $\quad\left(\partial \mathrm{L} / \partial_{t} \lambda\right)=\left[\Sigma\left(w_{t}(T) /(1+i)^{t-1}\right)-\Sigma\left(p X_{t}+w S_{t}\right) /(1+i)^{t-1}\right]=0$.

Dividing equation (A1b) by $\lambda$ yields the expression

(A2) $\left[\mathrm{U}_{\mathrm{s}} \mathrm{v}^{\prime}(.) \varepsilon\right] / \lambda=\Sigma \mathrm{w} /(1+\mathrm{i})^{\mathrm{t}-1}$.

Equation (A2) provides the basis for empirical analysis. 
often do you attend church or religious services?" A summary of the responses to the religious service attendance question used in the empirical analysis is given in Table 1. We have ordered the frequency of attendance in such a way that larger values indicate greater frequency of attendance. We have also deleted the "don't know" category (a total of 4 observations) to keep the measure less ambiguous.

TABLE 1

Frequency Table for the Dependent Variable

\begin{tabular}{lcc}
\hline Participation & Frequency & Percent \\
\hline Once a week or more & 443 & 39.0 \\
A few times a month & 222 & 19.6 \\
Once a month & 102 & 9.0 \\
A few times a year & 184 & 16.2 \\
Less often than that & 94 & 8.3 \\
Not at all & 86 & 7.6 \\
Don't know & 4 & 0.4 \\
\hline
\end{tabular}

The choice variable is qualitative and ordered from "not at all" to "once a week or more." In other words, it is a categorical dependent variable. We therefore use ordered probit models as a framework for analysis of the responses (see Maddala 1983; Greene 1993). The ordered probit model is a maximum likelihood method that estimates values for the model parameters when the dependent variable is an ordered categorical one. The ordered probit model distinguishes between a dependent variable of theoretical importance that is unobserved and the observed dependent variable or response variable (ordering for church attendance). The ordered probit model is based on the following specification:

$$
\begin{aligned}
& y_{i}^{*}= \beta^{\prime} x_{i}+\varepsilon_{i}, \\
& \varepsilon_{i} \sim N[0,1], \text { and } \\
& y_{i}=0 \text { if } y_{i}^{*} \leq \mu_{0}, \\
& 1 \text { if } \mu_{0}<y_{i}^{*} \leq \mu_{1}, \\
& 2 \text { if } \mu_{1}<y_{i}^{*} \leq \mu_{2}, \\
& \quad \ldots \\
& \quad \text { if } y_{i}^{*}>\mu_{J-1} .
\end{aligned}
$$

The observed counterpart to $y_{i}^{*}$ is $y_{i}$, or religious service attendance. The ordered probit model assumes that the explanatory variables are linearly associated with the latent dependent variable, which in turn is associated with the response variable via threshold variables (Maddala 1983). Threshold parameters are calculated in the estimation procedure, along with their significance levels, to provide measures of the significance of ratings of alternatives. In the context of this paper, an individual rates alternatives (frequency of religious service attendance) when utility exceeds a threshold or critical level of satisfaction.

Religious participation or religiosity is not limited to one particular religion, but the sample is dominated by Protestant denominations (84 percent). The other religions identified are Catholics ( 4.3 percent), Jews ( 0.3 percent), and 
other (11.5 percent). ${ }^{3}$ Two ordered probit models were estimated-one without nonlinear terms (Model 1) and one with nonlinear terms (Model 2)-in order to investigate the nonlinear relationships between religious participation and income, education, and age of respondents.

\section{Explanatory Variables}

Explanatory variables used in the analysis were selected as suggested by the conceptual framework and by earlier work to best represent various motives that are hypothesized to encourage individuals to attend religious services. Although we have attempted to group these variables into three categories (consumptive motive, social pressure motive, and afterlife motive) there are no clear distinctions and some of them may be used to measure more than one motive.

The economic and demographic factors that we include are age, sex, race, income level, marital status, and education. The theory of investment in "religious" capital developed by Azzi and Ehrenberg (1975) concludes that it is optimal for individuals to invest more (in religious capital) in the latter part of the life cycle because the expected returns will not be generated until death. ${ }^{4}$ This leads to the hypothesis that religious participation is positively associated with age. In contrast, Long and Settle (1977) find a negative relationship between age and religious participation for a sample of Wisconsin households. Given these contradictory findings, we will test a related hypothesis that age actually has a convex (U-shaped) relationship with religious participation.

It is hypothesized that women tend to participate in religious activities more than men. Azzi and Ehrenberg (1975) attribute this to lower market wages for women. It is also hypothesized that nonwhites participate in religious activities more than whites. Azzi and Ehrenberg (1975) conclude that racial discrimination may take the form of limiting the participation of nonwhites in formal markets, which gives them more time for other activities thus leading to higher nonwhite religious participation.

A major weakness of the survey is its failure to include a specific measure of the wage rate of the respondents. A crude proxy is used to measure individuals' incomes. Although the aggregate level of income for each respondent was asked in the survey, it has many missing observations, and therefore cannot be used in the analysis. Respondents' level of relative income in the community was asked in another question and this is used as a proxy for the income variable (income level). Respondents were asked whether their level of income in the community is higher, average, or lower, and responses were measured on a five-point scale, ranging

\footnotetext{
${ }^{3}$ Earlier drafts on this data set estimated separate equations for Protestants and non-Protestants, but this was abandoned for several reasons. The sample was dominated by the Protestant denomination (84 percent). Among Protestants, the results are similar to that of the full model (results are not reported in the paper). Other religions/denominations represented in the sample were Catholics ( 4.3 percent) and Jews ( 0.3 percent). The number of observations available for these two categories was simply not large enough to warrant separate estimations. The largest non-Protestant category was "other," but no further details of the makeup of this category were available. We have realized that the non-Protestant category is too diversified to be grouped into a single category and may give wrong implications if included in one category.

${ }^{4}$ It has also been argued (see Neuman 1986) that this may be explained as the outcome of a process of habit formation.
} 
from 1 (a lot lower) to 5 (a lot higher). ${ }^{5}$ Lower economic status may force individuals to work more hours to secure additional income, leaving them with less time for attending religious services. On the other hand, a higher income level might raise the opportunity cost of time, which leads to additional work effort (Sawkins, Seaman, and Williams 1997). Also, some sociologists (Goode 1966; Alston and McIntosh 1979) suggest that religious participation should be higher among the lower-class members, who are presumably faced with more socioeconomic deprivation and alienation than the upper-class members. Given those ambiguities, we will rely upon empirical results to resolve the confusion in the context of the rural South. ${ }^{6}$

Researchers present mixed evidence on the association of education with religious participation. Several studies find education to be positively associated with religious service attendance (Neuman 1986; Iannaccone 1998; Sawkins, Seaman, and Williams 1997). Some sociological studies contend that religious participation may be higher among the less educated due to "the alienating consequences of deprivation" (Alston and McIntosh 1979). Stark, Iannaccone, and Finke (1996) point out that although the correlation between educational attainment and religiosity is positive, a downward trend may occur at the highest level of educational attainment. Again, we appeal to our empirical results to resolve this riddle.

We use civic engagement as a measure of social capital or the social pressure motive. A question that was indicative of the civic engagement (things people do about government or the political and social sphere) of the residents of the rural South was available in the survey. The list of indicators includes: having written or called any politician; having attended a political party rally; having attended a public meeting on town or school affairs; having worked for a political party; having served on a committee for some local organization; having held or run for a political office; having signed a petition; having made a speech; having been an active member of any group that tries to influence public policy or government; having written to a newspaper; etc. Our measure of the intensity of participation in various activities (civic) is the total number of activities cited per each respondent. Civic activity is hypothesized to be positively associated with religious service attendance. Family itself is a key form of social capital. The breakdown of the traditional family unit has been proposed as a reason for the downturn in civic engagement (Putnam 1996). Putnam (1996) argues that married men and women rank somewhat higher on measures of social capital and says that single people are significantly less trusting and less engaged in civic activities than married people.

Several variables are included to measure individuals' afterlife motive. They are word of God (Bible is the word of God recorded without mistakes), born agair, 'have been "born again"), and belief, respondents' ratings on how much reli-

\footnotetext{
${ }^{5}$ After accounting for missing values, the proxy income level variable had a 64 percent first-order correlation with the income variable.

${ }^{6}$ The rationale for higher-income people attending religious services more may not be purely economic. For example, rural business leaders can network and build better business relationships at church. (We thank one of our reviewers for this comment).
} 
gious beliefs influence their opinions on other topics, such as politics, economics, and education. These variables are expected to have a positive association with religious service attendance.

\section{Estimation and Results}

The ordered probit models were estimated using the LIMDEP econometric software package (Version 7.0). Summary statistics of the regressors used in the empirical models are presented in Table 2. Two models were fitted to 1,135 observations.

TABLE 2

Summary Statistics for Explanatory Variables

\begin{tabular}{|c|c|c|c|c|c|}
\hline Variable & Explanation & Mean & Std.D & Min & Max \\
\hline Belief & Religious beliefs affect other topics: & & & & \\
\hline & $1=$ not at all to $5=\mathrm{a}$ lot & 3.687 & 1.452 & 1 & 5 \\
\hline \multirow[t]{2}{*}{ Word of God } & Bible is the word of God recorded without mistakes: & & & & \\
\hline & $1=$ yes, $0=$ no & 0.710 & 0.454 & 0 & 1 \\
\hline Born again & Have been "born again": $1=$ yes, $0=$ no & 0.732 & 0.443 & 0 & 1 \\
\hline Married & Marital status: $1=$ married, $0=$ otherwise & 0.578 & 0.494 & 0 & 1 \\
\hline Education & Scale: $1=$ no school, $2=$ grade school, $3=$ some & & & & \\
\hline \multirow{3}{*}{ Income level } & college, $6=$ college graduate, and $7=$ post graduate & 4.060 & 1.287 & 1 & 7 \\
\hline & $\begin{array}{l}\text { Level of income in the community: } 1=\text { a lot lower, } \\
2=\text { a little lower, } 3=\text { about average, } 4=\text { somewhat }\end{array}$ & & & & \\
\hline & higher, and $5=a$ lot higher & 2.850 & 0.959 & 1 & 5 \\
\hline Age & Age in years & 44.606 & 16.809 & 19 & 75 \\
\hline Sex & 1 if male, 0 if female & 0.484 & 0.500 & 0 & 1 \\
\hline Race & 1 if white, 0 otherwise & 0.803 & 0.398 & 0 & 1 \\
\hline Civic & $\begin{array}{l}\text { Count variable: } 0=\text { did not participate any civic } \\
\text { activities listed to } 12=\text { participated in all } 12\end{array}$ & 0.859 & 1.783 & 0 & 12 \\
\hline
\end{tabular}

Collinearity is not excessive in this data set. ${ }^{7}$ The tests for heteroskedasticity are implemented through an alternative formulation of the model with an embedded correction for multiplicative heteroskedasticity. Error variance is assumed to be a function of respondents' age. ${ }^{8}$ The likelihood ratio statistics testing the homoskedasticity assumption in the context of this formulation indicate that the model with the specification for heteroskedasticity predicts slightly better. As a measure of overall fit, a chi-square test for the null hypothesis that all coefficients except the intercept are zero is computed and the null hypothesis is rejected at the 0.00 significance level for both models.

Table 3 presents estimates and the threshold parameters of the empirical equations. Specification test results, using estimates of the threshold variables, are listed in the third part of Table 3. The threshold variables can be interpreted as the

\footnotetext{
${ }^{7}$ Tolerance values were calculated (using SAS) as a measure of the strength of interrelationships among regressor variables in the model. Tolerance for a variable is defined as $1-R^{2}$, where $R^{2}$ is obtained from the regression of the variable on all other regressors in the model. If all variables are orthogonal to each other, tolerance is 1 . If a variable is very closely related to other variables, tolerance goes to zero. This statistic is also related to the variance inflation factor (VIF) as VIF $=1$ /Tolerance. Our results indicated that all the variables had a tolerance value closer to 1 (the lowest value was 0.74 ).

${ }^{8}$ Given cross-sectional data, the errors will most likely be heteroskedastic. Source of heteroskedasticity was obtained by plotting residuals from a model with homoskedasticity against continuous variables in the sample (education and age) and it was revealed that residuals were an increasing function of age and no systematic pattern was revealed between residuals and education.
} 
numerical linkages between the utility function of the respondents and preference ratings given by the frequency of religious service attendance. Model coefficients can be interpreted as the probability of an individual choosing how often to attend religious services. A positive sign on a coefficient indicates an increase in the log of the odds ratio, and higher values for the parameter estimates imply greater attendance at religious services.

TABLE 3

Ordered Probit Regression Results

\begin{tabular}{|c|c|c|c|c|}
\hline \multirow[b]{2}{*}{ Variable } & \multicolumn{2}{|c|}{ Model 1} & \multicolumn{2}{|c|}{ Model 2} \\
\hline & Coefficient & t-ratio & Coefficient & t-ratio \\
\hline Constant & -3.258 & 4.370 & -5.947 & 2.992 \\
\hline Belief & 1.145 & $9.070^{* *}$ & 1.318 & 8.984 \\
\hline Word of God & 0.770 & $2.751^{* *}$ & 0.847 & $2.566^{* *}$ \\
\hline Born again & 2.497 & $7.062^{* *}$ & 1.801 & 1.549 \\
\hline Married & 0.628 & $2.464^{*}$ & 0.831 & $2.685^{* *}$ \\
\hline Education & 0.369 & $3.444^{* *}$ & 2.041 & $3.171^{* *}$ \\
\hline Income & 0.322 & $2.584^{* *}$ & 1.492 & $2.127^{*}$ \\
\hline Age & 0.036 & $4.475^{* *}$ & -0.066 & -1.383 \\
\hline Sex & -0.605 & $2.484^{* *}$ & -0.718 & $2.518^{* *}$ \\
\hline Race & -1.181 & $3.287^{* *}$ & -1.412 & $3.347^{* *}$ \\
\hline Civic & 0.190 & $2.433^{*}$ & 0.271 & $2.921^{* *}$ \\
\hline Edusq & & & -0.228 & $2.096^{*}$ \\
\hline Incomesq & & & -0.194 & $2.785^{* *}$ \\
\hline Agesq & & & 0.001 & $2.376^{* *}$ \\
\hline Born ${ }^{*} e d u$ & & & 0.137 & 0.580 \\
\hline Born*inc & & & 0.171 & 0.509 \\
\hline \multicolumn{5}{|c|}{ Variance Function } \\
\hline Log(age) & 0.351 & $14.215^{* *}$ & 0.389 & $15.389^{* *}$ \\
\hline \multicolumn{5}{|c|}{ Threshold Parameters ${ }^{\mathrm{a}}$} \\
\hline $\mathrm{Mu}(1)$ & 1.899 & $8.632^{* *}$ & 2.205 & $8.535^{* *}$ \\
\hline $\mathrm{Mu}(2)$ & 4.517 & $10.519 * *$ & 5.251 & $10.297^{* *}$ \\
\hline $\mathrm{Mu}(3)$ & 5.652 & $10.914^{* *}$ & 6.569 & $10.676^{* *}$ \\
\hline $\mathrm{Mu}(4)$ & 7.982 & $11.144^{* *}$ & 9.269 & $10.851^{\text {** }}$ \\
\hline
\end{tabular}

T-statistics are in absolute values.

Significance levels: ${ }^{* *}=1 \%$ or lower, ${ }^{*}=$ between $1 \%$ and $5 \%$.

aThreshold variables link the utility of respondents to numerical ratings.

All the variables in Model 1 are statistically significant and those variables for which signs were predicted have the expected signs. The results confirm many of the findings of prior studies. The results also provide strong support for testing for more than one motive for participation in religious activities. The linear part of the income variable is positive and significant, indicating that those individuals who feel that they are richer in the community attend more religious services. However, a negative sign on the quadratic term of this variable (incomesq) in Model 2 yields a concave income-religious participation profile. Thus, religious service attendance is increased when income increases at the lower level of incomes, but at higher levels the effect of higher income diminishes. Similarly, the effect of education in the linear form is positive and significant. However, a negative sign for the quadratic term of this variable (edusq) in Model 2 yields the same implications to as for income. Religious service attendance is increased when edu- 
cation increases for lower education levels, but at higher levels of education the marginal effect of education goes down.

Age is a very strong predictor, indicating that older people tend to attend more religious services. The quadratic specification for the age variable reveals a U-shaped age-religious participation profile. ${ }^{9}$ This may be explained as a result of individuals' willingness to spend more time on investing in human capital in the early stages of their lives ${ }^{10}$ (hence less time on religious participation) and more time on investing in religious capital in the latter stages of their life cycle because the expected returns are much closer to being realized. Females attend religious services more than males. Race carries a negative sign, indicating that nonwhites tend to attend religious services more frequently than whites. This result reconfirms the hypothesis in Azzi and Ehrenberg (1975) that the social value of religious participation is higher for racial minorities.

Three afterlife variables are included to capture factors that influence the afterlife utility the individual receives from participating in religious activities. They are, word of God (Bible is the word of God recorded without mistakes), born again (have been "born again"), and belief (religious belief affects other aspects of life). These variables are proxies for the belief in afterlife and faith in God and they are positive and highly significant, indicating that these three variables are major determinants of religious service attendance in the rural South. A Wald test under the null hypothesis that the coefficients of the afterlife variables as a group are zero is performed. The chi-square statistic is 9.040 at zero probability level, and this indicates that the null hypothesis is rejected. This finding suggests that substantial specification error would occur if this group of variables were not used in the estimation, confirming the belief that there are multiple motives influencing religious participation.

Interaction terms of the income class and education variables with the born again variable (born*inc and born*edu) were included in Model 2 to determine whether the effects of income level and education on religious participation diminish with the level of commitment. ${ }^{11}$ Results show that both of these variables are statistically insignificant, indicating that the effects of income and education do diminish in the most committed individuals. This result also suggests that the different classes of motives are not strongly related.

Results also indicate some evidence for a social capital motive for religious service attendance. The civic variable is positive and significant indicating that rural Southerners who participate in civic activities tend to participate more in religious services. Married individuals participate more in religious services than those who are not married, divorced, or widowed. A Wald test under the null hypothesis that the coefficients of social capital variables as a group are zero is performed. The chi-square statistic is 3.068 at zero probability level and this indicates that the null hypothesis is rejected.

\footnotetext{
${ }^{9}$ Similar results were obtained by Sullivan (1985)

${ }^{10}$ This will enable individuals to get back the returns from the investments for a larger number of years (Azzi and Ehrenberg 1975).

${ }^{11}$ We are thankful to one of our reviewers for this important extension.
} 


\section{CONCLUSIONS}

Economic, socio-demographic, and attitudinal factors can be incorporated to explain variation in religious service attendance in the rural South. Taken together, these results appear to lend support to the commonly accepted belief that in the rural South the tendency to attend religious services frequently is strong among those who are more educated and of a higher income class. Our results also reaffirm a higher propensity for older, married, female, and nonwhite individuals to attend religious services more frequently. On the other hand, the results also imply that in the rural South less religiosity is associated with those who are less educated, of a lower income class, unmarried or divorced, male, young, members of the less-civic sections of the population, and those who have no faith in God or an afterlife.

Our results support the conclusion that an allocation of time framework, in terms of income, education, and age, is helpful in explaining the amount of time spent on religious activities. It also strongly supports the inclusion of other noneconomic variables that can measure salvation and social capital motives in an analysis of religious behavior. Finally, our findings suggest that individuals' participation in religious services or, in economic terms, their demand for religious services goods is a complex function of economic and social conditions as well as the degree of belief in the afterlife and not simply a function of one motive.

This study also shows that even though the rural South is claimed to be more religious than the rest of the nation, we find no significant differences between the rural South and the United States. ${ }^{12}$ The studies that use national data have found age, income, and education to be positively and significantly associated with religious service attendance (Iannaccone 1998). They also show that women and nonwhites tend to participate more in religious service attendance (Iannaccone 1998). Some of these studies also show that belief in God and afterlife is significantly and positively associated with religious service attendance (Iannaccone 1998).

The case for multiple motives or extra-economic interpretation of religious participation in the rural South seems to be substantially strengthened by our results. Any attempt to exclude these noneconomic variables from an analysis of religious participation and to limit the analysis to pure economic variables will cause serious misspecification errors. Further, since religious establishments are widely considered to be a source of social capital, and we show a positive and significant relationship between religious attendance and higher levels of social capital in individuals, there is support for the notion that religious establishments can play a positive role in community development activities.

\footnotetext{
${ }^{12}$ It may have been more useful if we were able to compare the rural South with the rest of the nation but we have been unable to find a study that excludes the rural South from the rest of the United States.
} 


\section{REFERENCES}

Akerlof, G.A. "A Theory of Social Custom, of Which Unemployment May Be One Consequence." Quarterly Journal of Economics 94 (1980), 749-75.

Alston, J.P., and W.A. McIntosh. "An Assessment of the Determinants of Religious Participation." Sociological Quarterly 20 (1979), 49-62.

Anderson, G.M. "Mr. Smith and the Preachers: The Economics of Religion in the Wealth of Nations." Journal of Political Economy 96 (1988), 1066-88.

Azzi, C., and R. Ehrenberg. "Household Allocation of Time and Church Attendance." Journal of Political Economy 83 (1975), 27-53.

Becker, G.S. The Economic Approach to Human Behavior. Chicago, IL: University of Chicago Press, 1976. . "A Theory of Allocation of Time." Economic Journal 75 (1965), 493-517.

Bergin, A.E. "Religiosity and Mental Health: A Critical Reevaluation and MetaAnalysis." Professional Psychology: Research and Practice 14 (1983), 170-84.

Chalfant, H.P., and P.L. Heller. "Rural/Urban versus Regional Differences in Religiosity." Review of Religious Research 33 (1991), 76-86.

Durkin, Jr., J.T. and A.M. Greeley. "A Model of Religious Choice Under Uncertainty: On Responding Rationally to the Nonrational." Rationality and Society 3 (1991), 178-196.

Fichter, J.H., and G.L. Maddox. "Religion in the South: Old and New." In J. McKinny and E. Thompson (eds.) The South in Continuity and Change. Durham, NC: Duke University Press, 1965.

Goode, E. "Social Class and Church Participation." American Journal of Sociology 72 (1966), 102-111.

Greene, W.H. Econometric Analysis. New York: Macmillan Publishing Company, 1993. Harriss, J., J. Hunter, and C.M. Lewis. "Introduction." In J. Harriss, J. Hunter, and C.M. Lewis (eds.) The New Institutional Economics and Third World Development. London: Routledge, 1995.

Hirschleifer, J. "The Expanding Domain of Economics." American Economic Review 75 (1985), 53-68.

Hurlbert, J.S. "The Southern Region: A Test of the Hypothesis of Cultural Distinctiveness." The Sociological Quarterly 30 (1989), 245-66.

Iannaccone, L.R. "Introduction to the Economics of Religion." Journal of Economic Literature 36 (1998), 1465-95.

. "Religion, Values, and Behavioral Constraint." Prepared for the Symposium on the Economic Analysis of Social Behavior, Chicago, IL, December 1996.

Kanagy, C.L., G. Firebaugh, and H.M. Nelsen. "The Narrowing Regional Gap in Church Attendance in the United States." Rural Sociology 59 (1994), 515-24.

Kuran, Timur. "Islam and Underdevelopment: An Old Puzzle Revisited." Journal of Institutional and Theoretical Economics 153 (1997), 41-71. 
Long, S.H., and R.F. Settle. "Household Allocation of Time and Church Attendance: Some Additional Evidence." Journal of Political Economy 85 (1977), 409-13.

Maddala, G.S. Limited Dependent and Qualitative Variables in Econometrics. New York: Cambridge University Press, 1983.

Neuman, S. "Religious Observance within a Human Capital Framework: Theory and Application." Applied Economics 18 (1986), 1193-1202.

Novak, M. Will It Liberate? Questions about Liberation Theology. New York: Paulist Press, 1986.

Putnam, R.D. "The Strange Disappearance of Civic America." The American Prospect 24 (1996), 1-16.

Reed, J.S. "The Cardinal Test of a Southerner: Not Race but Geography." Public Opinion Quarterly 37 (1973), 232-240.

. Southerners: An Essay in the Social Psychology of Sectionalism. Chapel Hill: University of North Carolina Press, 1983.

Sawkins, J.W., P.T. Seaman, and H.C.S. Williams. "Church Attendance in Great Britain: An Ordered Logit Approach." Applied Economics 29 (1997), 125-34. Smith, I., J.W. Sawkins, and P.T. Seaman. "The Economics of Religion Participation: A Cross-Country Study." Kyklos 51 (1998), 25-43.

Stark, R. "Psychopathology and Religious Commitment." Review of Religious Research 12 (1971), 165-76.

Stark, R., L.R. Iannaccone, and R. Finke. "Linkages between Economics and Religion." American Economic Review 86 (1996), 433-37.

Sullivan, D.H. "Simultaneous Determination of Church Contributions and Church Attendance." Economic Inquiry 23 (1985), 309-20.

Ulbrich, H., and M. Wallace. "Church Attendance, Age, and Belief in the Afterlife: Some Additional Evidence." Atlantic Economic Journal 11 (1983), 44-51.

Varian, H.R. Micoeconomic Analysis. New York: W.W. Norton \& Company, 1992.

Von Neumann, J., and O. Morgenstern. Theory of Games and Economic Behavior. Princeton, NJ: Princeton University Press, 1947. 